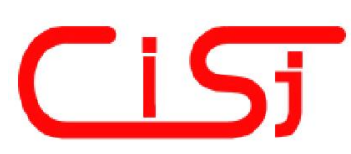

\title{
COGNITIVE SYSTEM OF THE HEPATORENAL SYNDROME SCREENING IN PERSONS WITH ALCOHOL ABUSE
}

\author{
Alexey Lagunov, Darina Lagunova, Irina Berdennikova \\ Northern (Arctic) Federal University \\ Severnaya Dvina Emb. 17, Arkhangelsk, Russia, 163002, \\ E-mail: a.lagunov@narfu.ru,d.lagunova@narfu.ru, i.berdennikova@narfu.ru,http://www.narfu.ru/
}

\begin{abstract}
Increase in alcohol consumption is observed in all countries of the world. Over the past 20 years, consumption of alcohol correlated with the level of mortality from liver cirrhosis. Under the hepatorenal syndrome understand the primary lesion of the liver with subsequent involvement in the painful process of kidney tissue. In order to detection of hepatorenal syndrome in medical practice screening laboratory markers carried out manually. Introduction of medical information system can significantly improve the process of detecting disease in patients. The authors were unable to find an analogue of medical information system for the purpose of screening for hepatorenal syndrome. Analysis of the process of screening laboratory markers of hepatorenal syndrome allowed to create a clientserver intelligent information system based on the Java SE platform using the management system database Firebird. Tests were carried out Arkhangelsk City Clinical Hospital № 1. Testing has shown that the time of diagnosis was reduced in comparison with traditional methods at $69 \%$, with fewer specialists, while job satisfaction of physicians increased by $23 \%$. Diagnostic accuracy hepatorenal syndrome is not dependent on the method of diagnosis. Testing program showed that the data that gives our program coincide with those of health professionals. Copyright (C) Research Institute for Intelligent Computer Systems, 2014. All rights reserved.
\end{abstract}

Keywords: hepatorenal syndrome; screening; workstation; styling.

\section{INTRODUCTION}

Computers and information technology became for a long time already an integral part of the most different spheres of a life, and the medicine didn't become an exception. Doctors advise patients online, the diagnostic apparatus is equipped by powerful processors, conferences and consultations are spent through the Internet. And nowadays a medical information technology gets the increasing urgency, and the medical software becomes more and more claimed.

Medical information systems implementation is capable to improve considerably working processes at the most different levels: beginning from the medical automated workplace creation in separate medioprophilactic institution before complex automation of polyclinics and hospitals at regional level.

The urgency of research issue is caused by that the hepatorenal syndrome problem is actively studied more than 100 years, however remain unresolved some question on treatment of such patients, therefore the high death rate remains.

In connection with the extremely unfavorable prognosis for the first type hepatorenal syndrome and the given complication hepatocirrhosis prevalence at working-age people, it is required to reveal as soon as possible at an early stage its presence and in due time to institute corresponding therapy.

The increase in alcohol consumption is marked worldwide. Russia leads in the world on negative biomedical and social consequences of spirit consuming.

Analysis original sources of the research problem showed that the syndrome hepatolienal diagnosis is performed manually on the basis of laboratory studies and examination of patients by the doctors.

To our regret, any program, allowing automate the process hepatorenal syndrome screening, is not found that.

Automating process of revealing diagnostics hepatorenal syndrome is need to health workers. Our papers is devoted to develop one of such program and show results of improving result of work of health worker in this direction.

\section{THE HEPATORENAL SYNDROME}

In 1793 Matthew Bailey informed on connection of hepatocirrhosis with drinking. For the last 20 
years alcohol consumption correlates with a death rate from a hepatocirrhosis. Annually 20 thousand persons in the world dies of hepatocirrhosis complications, $60 \%$ from them are working-age people [1].

Hepatorenal syndrome (HRS) - is serious form of kidney failure functional character that develops in patients with advanced hepatic insufficiency, acute and chronic liver diseases (acute viral hepatitis, leptospirosis, yellow haemorrhagic fever, drugs poisons, poisons of hepatotoxic mushrooms and surrogate alcohol, liver cirrhosis with portal hypertension) in the absence of other causes of kidney failure (chronic kidney disease, urinary tract obstruction, receiving nephrotoxic drugs) [2].

The most common cause of HRS - is hepatic cirrhosis - the final stage of chronic liver disease. Life expectancy of these patients depends on the development of complications. The heaviest hepatocirrhosis complications are the hepatic coma, a thrombosis in system portal vein, a bleeding from the varicose veins of a gullet, hemorrhoids veins, the hepatorenal syndrome, a liver cancer formation [3].

Maintain these patients - is complex, demanding task of the doctor as the correct tactics of these patients, in some cases, allows patients to safely wait for a liver transplant, which is a radical and most effective treatment [4].

The hepatorenal syndrome (HRS) is primary lesion of a liver with the subsequent involving in disease process of a nephritic tissue. Depending on clinical presentations severity and prognosis A. Gines both co-authors distinguish I and II typeshepatorenal syndrome. The first type hepatorenal syndrome, characterised by an unfavorable clinical course with lethality $80-90 \%$, is more often observed at an alcoholic hepatocirrhosis. The clinical course of II type hepatorenal syndrome is more favorably. It develops at a hepatocirrhosis without heavy cellular insufficiency, and lifetime varies from 1 till 7 years [5].

In connection with the extremely unfavorable prognosis for the first type hepatorenal syndrome and the given complication hepatocirrhosis prevalence at working-age people, it is required to define a set of typical laboratory signs, characteristic for the given syndrome for creation of the first type hepatorenal syndrome laboratory markers screening.

During research it is surveyed 61 persons at the age from 32 till 60 years with the experience of alcohol abuse from 7.5 till 18 years, passing treatment in Arkhangelsk (the first city hospital, the fourth city hospital, the seventh city hospital), suffering the alcoholic hepatocirrhosis, complicated hepatorenal syndrome. The control group was made by almost healthy 15 men at whom the chronic alcoholism and taking alcoholic drinks within the last two weeks has been excluded clinically and anamnesticly. The hepatorenal syndrome catamnesis has been studied, the clinical, biochemical and instrumental methods of research and also a blood analysis on presence hepatitis markers HBV and $\mathrm{HCV}$ are made during research.

As a result of the research the following hepatorenal syndrome development predictors (prognostic parameters) have been revealed (Table 1) $[6]$.

Table 1. Clinical-laboratory signs occurrence frequency at patients with the first and the second types hepatorenal syndrome and control group.

\begin{tabular}{|c|c|c|c|c|}
\hline \multirow[t]{2}{*}{ Sign } & \multicolumn{2}{|c|}{$\begin{array}{l}\text { Patients } \\
\text { with I } \\
\text { type HRS }\end{array}$} & \multicolumn{2}{|c|}{$\begin{array}{l}\text { Patients } \\
\text { with II } \\
\text { type HRS }\end{array}$} \\
\hline & abs. & $\%$ & abs & $\%$ \\
\hline $\begin{array}{l}\text { Duration of a hepatocirrhosis } \\
\text { over } 5 \text { years }\end{array}$ & 11 & 50 & 8 & 21 \\
\hline $\begin{array}{l}\text { Duration of the alcoholization } \\
\text { period over } 1 \text { month }\end{array}$ & 8 & 36 & 8 & 21 \\
\hline $\begin{array}{l}\text { Presence of an accompanying } \\
\text { infection }\end{array}$ & 3 & 14 & 1 & 3 \\
\hline Hemorrhagic syndrome & 4 & 18 & 1 & 3 \\
\hline Marked icterus & 9 & 41 & 4 & 10 \\
\hline Hyperthermia & 6 & 27 & 2 & 5 \\
\hline $\begin{array}{l}\text { Cavitary and } \\
\text { edemata }\end{array}$ & 4 & 18 & 2 & 5 \\
\hline Encephalopathy presence & 15 & 68 & 16 & 41 \\
\hline $\begin{array}{l}\text { Hypotonia less than } 100 / 60 \\
\mathrm{~mm} \mathrm{Hg}\end{array}$ & 9 & 41 & 6 & 15 \\
\hline Resistant ascites & 21 & 96 & 11 & 28 \\
\hline $\begin{array}{l}\text { Tachycardia over } 100 \text { blows } \\
\text { per minute }\end{array}$ & 18 & 82 & 7 & 18 \\
\hline Leukocytes more than $15 * 10^{9}$ & 11 & 50 & 2 & 5 \\
\hline ESR over $30 \mathrm{~mm} \backslash$ hour & 12 & 55 & 17 & 44 \\
\hline Haemoglobin less than $90 \mathrm{~g} / \mathrm{l}$ & 16 & 73 & 1 & 3 \\
\hline $\begin{array}{l}\text { Thrombocytes less than } \\
150 * 10^{9}\end{array}$ & 16 & 73 & 3 & 8 \\
\hline $\begin{array}{l}\text { Bilirubin in } 10 \text { times above } \\
\text { norm }\end{array}$ & 13 & 59 & 3 & 8 \\
\hline Albumin less than $26,0 \mathrm{~g} / 1$ & 18 & 82 & 2 & 5 \\
\hline PTI less than $70 \%$ & 14 & 64 & 3 & 8 \\
\hline In total & 22 & 100 & 39 & 100 \\
\hline
\end{tabular}

In examined groups the average values of hematologic and biochemical indices, entering into routine examination at a hepatocirrhosis, are defined For revealing diagnostically significant laboratory signs (Table 2 and Table 3 ) [6].

The obtained data allows to reveal distinctive laboratory signs between the first and the second typeshepatorenal syndrome.

The hemogram high-informative indices for diagnostics the first type hepatorenal syndrome are:

- haemoglobin decrease less than $90.0 \mathrm{~g} / \mathrm{l}$;

- thrombocytes level 150*109 and more low; 
- leukocytes level 13*109 and above.

In the biochemical status diagnostically significant for the first type is:

- albumen decrease to $26.0 \mathrm{~g} / 1$ and more low;

- general and direct bilirubin increase in 10 times and more;

- alkaline phosphatase increase not exceeding two norms;

- lactate dehydrogenase (LDH) hepatic fraction increase in 2 times and more;

- creatinine increase in blood in 1.5-2 times;

- Na decrease in serum less than $128 \mathrm{mmol} / \mathrm{l}$.

Table 2. The table of the laboratory data average values at patients with the first and the second types hepatorenal syndrome and control group.

\begin{tabular}{|l|l|l|l|}
\hline Sign & $\begin{array}{l}\text { The control } \\
\text { group } \\
\text { n=10 }\end{array}$ & $\begin{array}{l}\text { Patients } \\
\text { with I type } \\
\text { HRS }\end{array}$ & P1 \\
\hline $\begin{array}{l}\text { Leukocytes *10 } \\
\text { (cell/l) }\end{array}$ & $7.40 \pm 1.30$ & $12.80 \pm 1.41$ & 0.010 \\
\hline Haemoglobin (g/l) & $138.30+0.85$ & $83.30 \pm 4.85$ & 0.001 \\
\hline $\begin{array}{l}\text { Thrombocytes *10 } \\
\text { (cell/l) }\end{array}$ & $246.20 \pm 12.5$ & $138.90 \pm 11.70$ & 0.001 \\
\hline ESR (mm/h) & $12.00 \pm 2.61$ & $39.30 \pm 5.05$ & 0.001 \\
\hline Whole protein (g/l) & $78.50 \pm 2.90$ & $66.00+3.11$ & 0.010 \\
\hline Albumin (g/l) & $38.70 \pm 2.90$ & $26.38 \pm 1.64$ & 0.001 \\
\hline $\begin{array}{l}\text { Total bilirubin } \\
(\mathrm{mmol} / \mathrm{l})\end{array}$ & $15.30 \pm 2.00$ & $311.68 \pm 39.90$ & 0.001 \\
\hline $\begin{array}{l}\text { Direct bilirubin } \\
(\mathrm{mmol} / \mathrm{l})\end{array}$ & $5.10 \pm 0.50$ & $235.86 \pm 32.19$ & 0.001 \\
\hline PTI (\%) & $80.65 \pm 1.49$ & $63.55 \pm 4.98$ & 0.010 \\
\hline APTT (s) & $36.20 \pm 1.40$ & $58.50 \pm 2.50$ & 0.001 \\
\hline AST (mmol/l) & $32.00 \pm 3.80$ & $124.70 \pm 19.49$ & 0.001 \\
\hline $\begin{array}{l}\text { Alanine- } \\
\text { aminotransferase } \\
\text { (mmol/l) }\end{array}$ & $26.00 \pm 3.10$ & $51.02 \pm 8.03$ & 0.010 \\
\hline K (mmol/l) & $3.70 \pm 0.06$ & $3.59 \pm 0.35$ & - \\
\hline Na(mmol/l) & $138.00 \pm 1.70$ & $123.27 \pm 3.80$ & 0.010 \\
\hline Ca (mmol/l) & $2.40 \pm 0.20$ & $1.35 \pm 0.21$ & 0.001 \\
\hline Fibrinogen (g/l) & $3.50 \pm 0.20$ & $3.10 \pm 0.43$ & - \\
\hline $\begin{array}{l}\text { Alkaline } \\
\text { phosphatase (un/l) }\end{array}$ & $154.40 \pm 5.30$ & $310.60 \pm 44.01$ & 0.010 \\
\hline GGTP (un/l) & $37.80 \pm 3.09$ & $423.67 \pm 75.72$ & 0.001 \\
\hline LDH (ME) & $276.40 \pm 3.20$ & $660.50 \pm 16.04$ & 0.001 \\
\hline $\begin{array}{l}\text { Creatinine } \\
(m c m o / / 1)\end{array}$ & $0.06 \pm 0.02$ & $0.22 \pm 0.03$ & 0.010 \\
\hline Urea (mol/l) & $6.30 \pm 1.10$ & $10.79 \pm 1.50$ & 0.050 \\
\hline
\end{tabular}

Indices constellation are statistically significant for screening the first type hepatorenal syndrome.

Thus, the developed hepatorenal syndrome screening with the help of accessible to any medioprophilactic institution laboratory research methods allows to raise diagnostics quality, with high probability degree to diagnose hepatorenal syndrome (I type or II type) to doctors of any speciality without the expert in stationary and ambulatory conditions, to solve questions concerning the prognosis and timely effective medication, to designate development hepatorenal syndrome preventive maintenance ways, to reduce period of patient stay with hepatorenal syndrome for a check-up and the expenses connected with it. Possessing sufficient simplicity and availability, low labor intensiveness, screening has high information value and can be applied to revealing of patients the first and the second typeshepatorenal syndrome.

Table 3. The table of the laboratory data average values at patients with the first and the second types hepatorenal syndrome and control group.

\begin{tabular}{|l|l|l|l|}
\hline Sign & $\begin{array}{l}\text { Patients } \\
\text { with II type } \\
\text { HRS }\end{array}$ & P2 & P1|P2 \\
\hline $\begin{array}{l}\text { Leukocytes *10 } \\
\text { (cell/l) }\end{array}$ & $9.40 \pm 0.67$ & - & 0.050 \\
\hline Haemoglobin (g/l) & $117.70 \pm 3.69$ & 0.001 & 0.001 \\
\hline $\begin{array}{l}\text { Thrombocytes } \\
* 10^{9}(\text { cell/l) }\end{array}$ & $184.90 \pm 13.19$ & 0.010 & 0.050 \\
\hline ESR (mm/h) & $38.10 \pm 3.87$ & 0.001 & - \\
\hline Whole protein (g/l) & $66.76+2.41$ & 0.010 & - \\
\hline Albumin (g/l) & $34.36 \pm 3.37$ & - & 0.050 \\
\hline $\begin{array}{l}\text { Total bilirubin } \\
\text { (mmol/l) }\end{array}$ & $190.88 \pm 28.06$ & 0.001 & 0.050 \\
\hline $\begin{array}{l}\text { Direct bilirubin } \\
\text { (mmol/l) }\end{array}$ & $151.30 \pm 18.49$ & 0.001 & 0.050 \\
\hline PTI (\%) & $70.07 \pm 3.08$ & 0.010 & - \\
\hline APTT (s) & $55.47 \pm 8.30$ & 0.010 & - \\
\hline AST (mmol/l) & $123.01 \pm 17.02$ & 0.001 & - \\
\hline $\begin{array}{l}\text { Alanine- } \\
\text { aminotransferase } \\
\text { (mmol/l) }\end{array}$ & $49.43 \pm 5.85$ & 0.001 & - \\
\hline K (mmol/l) & $3.59 \pm 0.11$ & - & - \\
\hline Na(mmol/l) & $130.05 \pm 1.40$ & 0.001 & 0.050 \\
\hline Ca (mmol/1) & $1.57 \pm 0.15$ & 0.001 & - \\
\hline Fibrinogen (g/l) & $3.37 \pm 0.39$ & - & - \\
\hline $\begin{array}{l}\text { Alkaline } \\
\text { phosphatase (un/l) }\end{array}$ & $467.36 \pm 38.78$ & 0.001 & 0.010 \\
\hline GGTP (un/l) & $627.40 \pm 23.84$ & 0.001 & 0.050 \\
\hline LDH (ME) & $482.88 \pm 52.18$ & 0.001 & 0.010 \\
\hline $\begin{array}{l}\text { Creatinine } \\
\text { (mcmol/l) }\end{array}$ & $0.21 \pm 0.06$ & 0.050 & - \\
\hline Urea (mol/l) & $9.60 \pm 1.20$ & 0.050 & - \\
\hline
\end{tabular}

\section{THE BASIC IDEAS FOR TASK IMPLEMENTATION}

Analysis of available medical software showed that developers are offered the following types of programs:

1. Programs in the first category are designed to maintain electronic document in a medical facility, the primary purpose of automation - is the task of shifting the doctors to work with electronic medical records. To a large extent, these programs represent an electronic storage of 
medical records of patients, with the possibility of fast data processing and information search.

2. Maintenance programs of medical equipment is usually supplied with the devices themselves. The main objective of these programs is to preserve the results of the survey in a universal format for use in other medical systems.

3. Program directories, which are databases for different purposes: Reference drugs, disease guides for therapists general practitioners and specialized expertise.

4. 3D atlases used mainly for educational purposes.

5. Program for the diseases diagnosis.

Last fifth category of programs is one of the smallest in the group of medical software. Most programs are reference information systems for specific diseases. Among the available programs is not found program for screening of hepatorenal syndrome in alcohol abusers.

For the implementation intelligent information system based on a database, comprising a system of interconnected entities have been put forward the following objectives:

1. You need to create managed database, which should be provided for introducing new data, editing data stored.

2. The program should be a server application with a thick client. It can be used both on a single computer or on a local network.

3. The projected database should include several related entities:

- general patient data;

- test results;

- list of medications;

- list of medical institutions.

4. When filling in the listed entity created by the program must be able to organize the search for the following:

- name and surname of the patient;

- after processing of patient data;

- Date entering the patient base.

5. Software product must process listed in the database of clinical trials results programmatically. In this case the problem of health worker in determining the syndrome will be minimized. The test results should entered and saved them. Everything else will make the program: analyze and process the data, identify the type of syndrome, if it is, compute the control coefficient for inspection and, if necessary, generate the necessary statistical report on patients. All this will help in the short term to diagnose the presence of symptoms and take timely action to treat because detection syndrome is a risk of death.
For realization of goals by selected software products must be nominated by a number of requirements:

- the use of a database located on a server and accessible to other users on the local network;

- create a product to be adapted for the operating system Windows, and Linux;

- database management system must carry large amounts of data storage;

- generated software product should be implemented based on the use of the available software tools.

Let us analyze the existing development tools. Initially, start with the programming language (Table 4).

Table 4. The comparative characteristic of programming languages.

\begin{tabular}{|c|c|c|c|c|}
\hline Parameter & C\# & Delphi & Java & Lazarus \\
\hline free access & - & - & + & + \\
\hline cross-platform & - & - & + & + \\
\hline $\begin{array}{l}\text { compile the application for } \\
\text { each operating system }\end{array}$ & & & - & + \\
\hline $\mathrm{VM}$ & - & - & + & - \\
\hline a wide range of features & + & + & + & + \\
\hline
\end{tabular}

Now, consider a database management system DBMS (Table 5).

Table 5. The comparative characteristic the DBMS.

\begin{tabular}{|l|l|l|l|l|}
\hline Parameter & & & & \\
\hline free access & - & + & + & - \\
\hline cross-platform & - & + & + & + \\
\hline client-server system & - & + & + & + \\
\hline $\begin{array}{l}\text { ability to store large } \\
\text { volumes of data }\end{array}$ & - & + & + & + \\
\hline small size distribution & - & + & - & - \\
\hline
\end{tabular}

Based on this analysis of existing software products on the market to achieve this goal will create a desktop-based application on the following technologies:

- Programming language - Java;

- Application Programming Interface (Eng. Application Programming Interface - API) - Swing;

- database management system (DBMS) Firebird.

Desktop-application will run on a "client-server", in other words, will be created "server application with a thick client."

Concerning the design of the user interface, the software product will be used NimbusLookAndFeel, 
proposed by developers Java. Nimbus - a standard design in Swing. All that is necessary for its use is JDK (or JRE). No additional libraries are not required, as all classes are within Java.

\section{THE PROGRAM «HEPATORENAL SYNDROMES CREENING»}

There are the various programs automating a workplace for the health workers, but computer analogues for diagnostics hepatorenal syndrome isn't developed yet. The revealed theoretical aspects of syndrome definition, significant indices, on which basis it is necessary to define syndrome presence, have been used by engineering of the computer program.

The program «Hepatorenal syndrome screening» is developed on the basis of platform Java SE [7] and database management system Firebird [8] and represents the client-server application.

The software product is developed for data processing optimisation, received as a medical examination result of the patient to reveal at abusers hepatorenal syndrome and definition of its type (I or II type). It possesses the simple and friendly interface that allows any medical worker (to the nurse, the laboratorian, the doctor) to use it in the presence of access to the application.

The program allows:

- to create the patient database, containing the general information, results clinical and biochemical indices of research, data on its hospitalisation, the assigned a medical preparations to a patient for treatment, type hepatorenal syndrome (at its presence);

- to generate reports for statistics about how many patients have I or II type hepatorenal syndrome, reports on the surveyed patients for the certain period.

The user interface workstation health worker in order to conduct screening of hepatorenal syndrome is needed to create a database of patients, detect the presence of the syndrome and the assignment necessary treatment and management of the medical history of these patients. At program startup (double-click the mouse on the file medicalARM.jar) login window appears. To access the application enter a user name and password.

After successful authorization, shows the main window of the application, which consists of three main parts: the top menu, search filter patients and patients list (Fig. 1).

The top menu allows you to exit the program automatically generate different types of reports, edit the list of medications prescribed for the treatment, edit the list of medical institutions, hospitalized patients, edit accounts for access to the application (add and remove users) to obtain information about the program, including guidance on the use. "Patients filter" allows you to work with an existing database, search by various parameters such as: name, patient name, date of making it to the database, the type of syndrome. The search can be carried out both on one and on several parameters by clicking the "Apply Filter". "Patient List" allows you to view a list of all patients registered in the database, a list of patients that meet the search parameters, and also includes the ability to add a new patient.

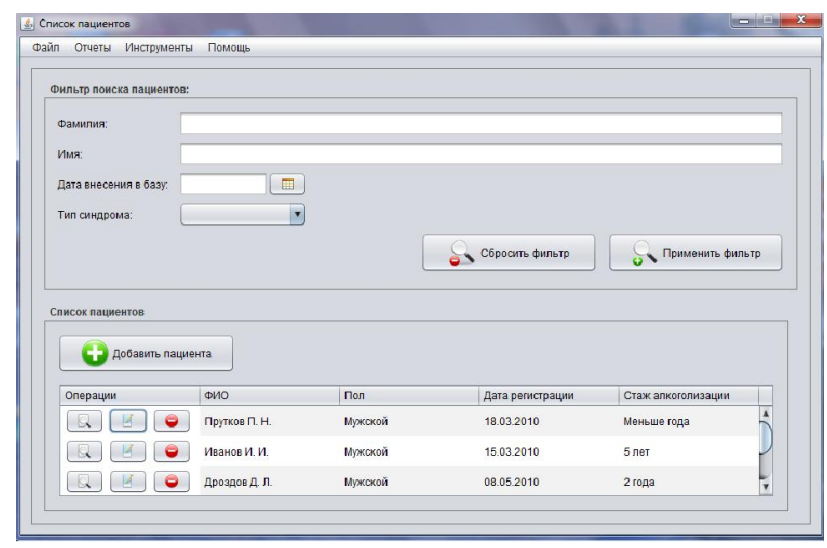

Fig. 1 - The program main window.

For example, a search for the type of syndrome. To do this, select from the drop down list "syndrome type I" and click "Apply Filter". In the lower section displays a list of patients with syndrome of the first type (Fig. 2).

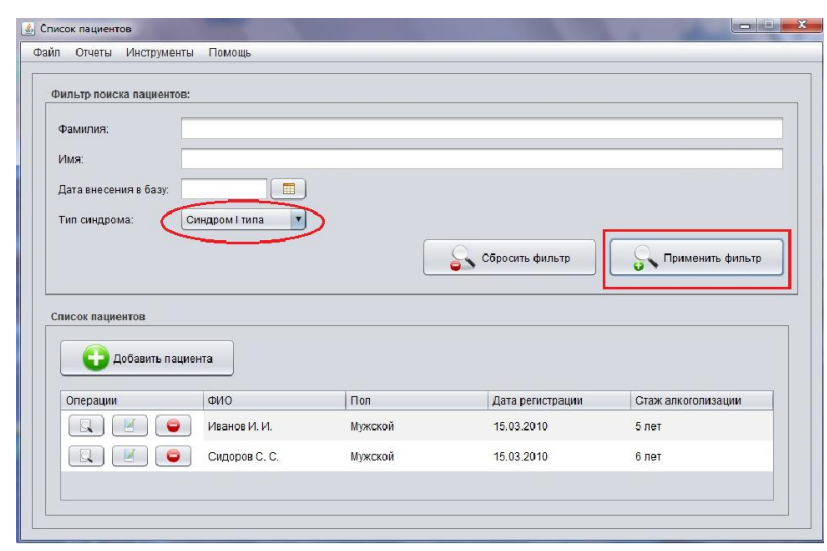

Fig. 2 - Filter usage.

Selecting the exact in the list of patients a particular patient, we can view detailed information about a given patient, edit information about it, or remove the patient from the database by using the corresponding buttons located on the left (Fig. 3). In order to avoid accidental deletion of a patient when you click on the "delete" a warning message stating that the patient will be removed from the database. 


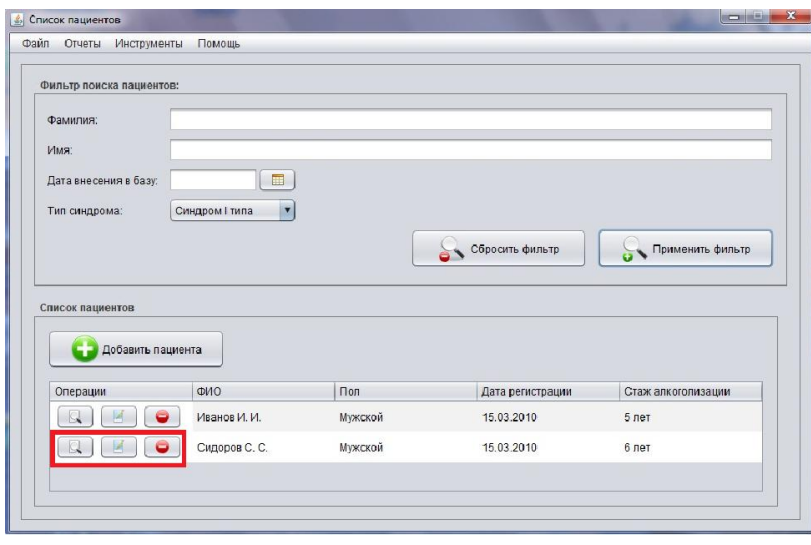

Fig. 3 - Work with patients data.

Furthermore, we can add a new patient to the database. To do this, click in main window, click "Add Patient" and a new form is appear (Fig. 4). Mandatory fields are the following fields: name, surname, patronymic patient, date of birth and the beginning of the abuse of alcohol. After you enter general information about the patient presses the button "Save". The patient will be saved in a database, entering basic data about a patient is inactive block of additional data about the patient, in which you enter the test results, the periods of hospitalization and prescribed medication for treatment.

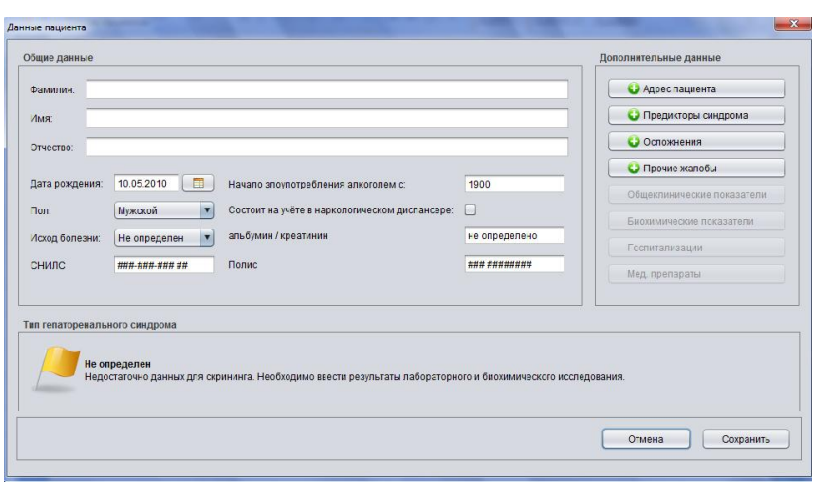

Fig. 4 - Adding the new patient at data base.

They will be active and available to fill only after saving the patient in the database. Type hepatorenal syndrome in this case is defined as sufficient data for screening must enter the results of biochemical and general clinical research. After the patient has been added to the database, we go back to the data of the patient and is able to enter the results of the analyzes (Fig. 5).Enter a general clinical results (Fig. 6).

Then enter the results of biochemical studies (Fig. 7). After entering the results common clinical and biochemical research press "Save" button, the program goes back to the original window, now if you view the data of the patient, it is already in the database to store information about the presence or absence of symptoms. As soon as you save the program on the basis of the input data determines the diagnosis and calculates the control factor - the ratio of albumin to creatinine (Fig. 8).

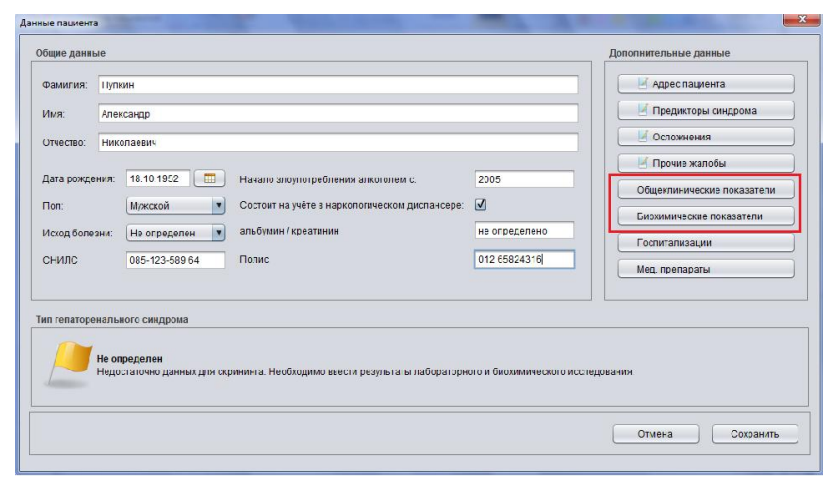

Fig. 5 - Saved in a patient database.

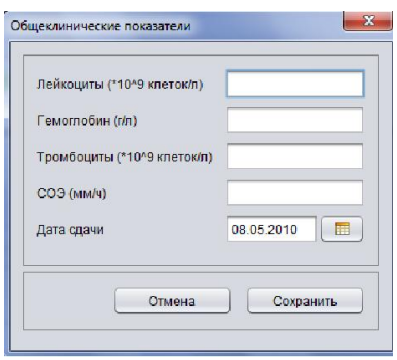

Fig. 6 - Enter the results of routine clinical research.

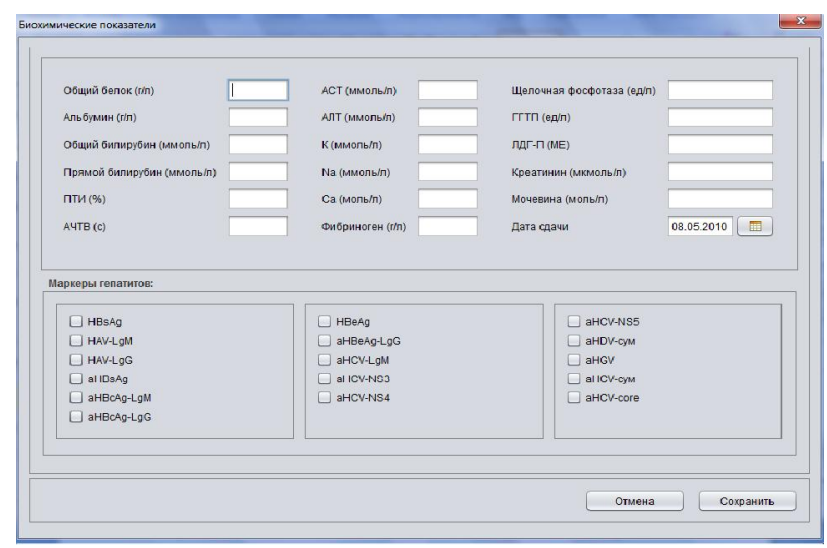

Fig. 7 - Enter the results of biochemical research.

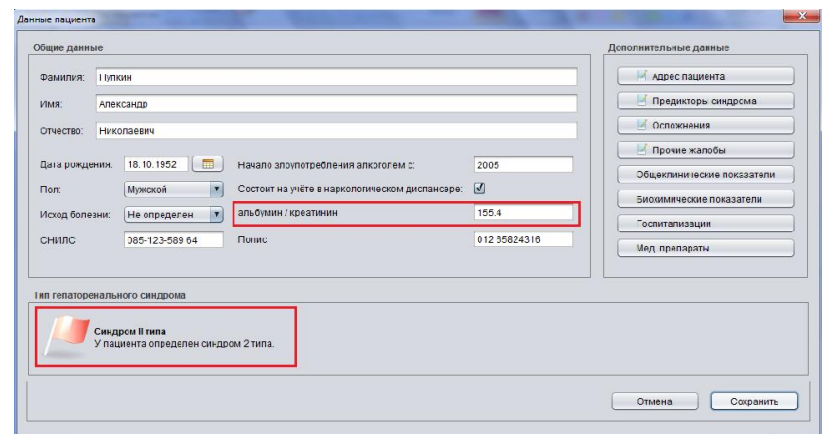

Fig. 8 - Result of determining the syndrome.

In the event that the patient will pass re-analysis, it is also capable of being added to the existing patient in the database, using the "Add results." All 
added results will be displayed as a separate line, which at any moment, you can view (Fig. 9).

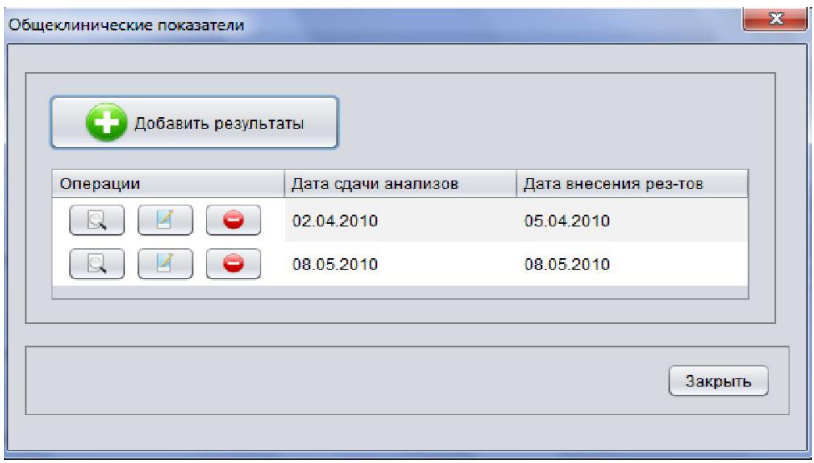

Fig. 9 - Displays in database test results.

And then, the program will again handle the data you entered, and on the basis of recent results to determine the syndrome. When it detects the syndrome in a patient, it should be appropriate treatment. Push the button "Med. drugs."There is a new form (Fig. 10). Push the button "appoint drug" and there is another form of "Appointment of medical drug "(Fig. 11). To select the name of the drug right click "..." The button. medication editor is (Fig. 12), which clicking on "+" button, select the appropriate drug. It will automatically appear in the first box, then fill the dose, date of start and end of the reception, the multiplicity of reception and if necessary any notes. And click "Save."

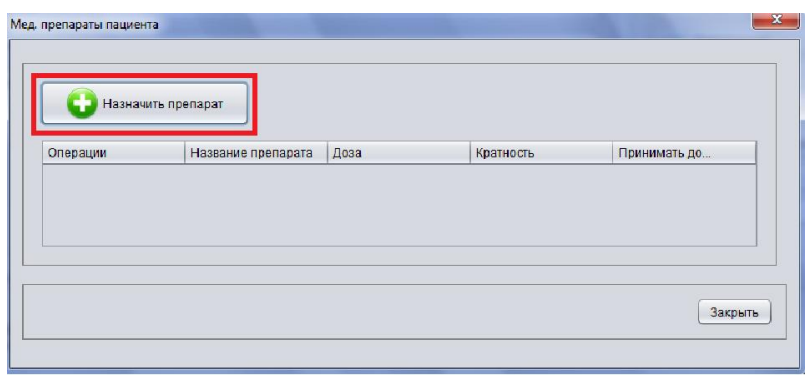

Fig. 10 - Medical drugs.

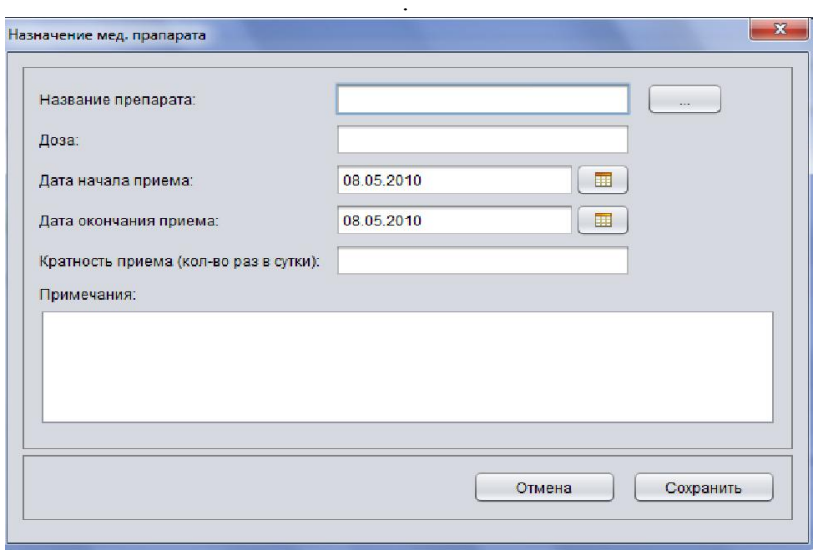

Fig. 11 - Medical drugs appointment.

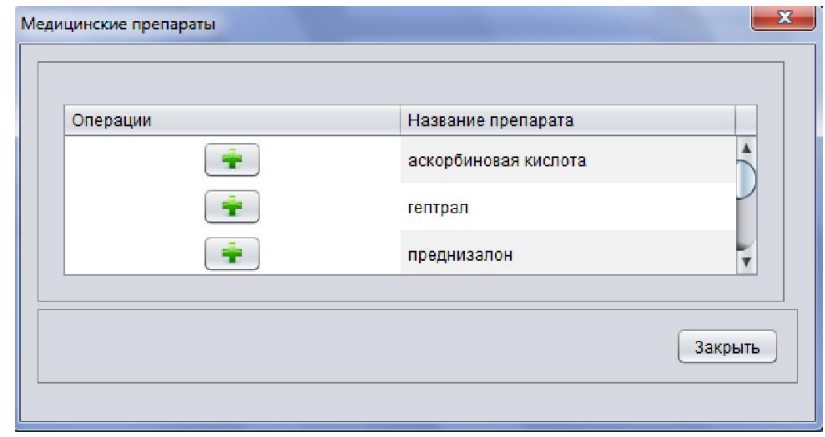

Fig. 12 - Editor medical products.

Analogously entered and other medical drugs, you can type several (Fig. 13). If the patient was hospitalized, all hospital admissions, we can also add to the database. Push in the data about the patient the "Hospitalization" and a new form (Fig. 14).

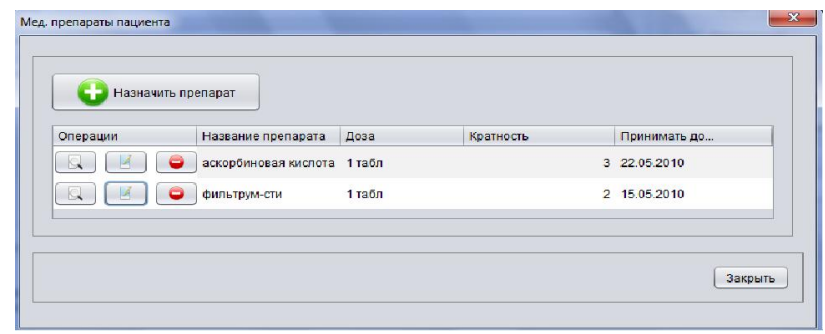

Fig. 13 - List of medical drugs prescribed to patient.

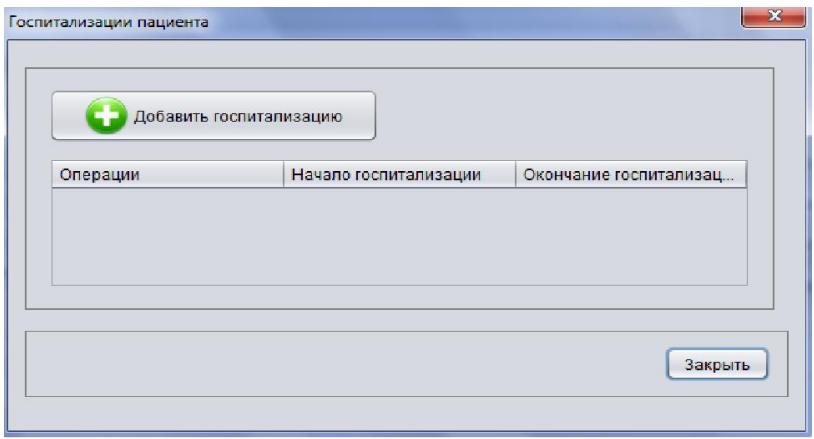

Fig. 14 - Hospitalizations.

Then, similarly as in the case of medical preparations click the 'Add hospitalization. "There is a new form in which we introduce the beginning, the end of hospitalization and place. Place of hospitalization is introduced as a medicine with an editor of medical institutions (Fig. 15). And it is obligatory click the button "Save". If necessary, management reporting and statistics, we can generate and store various types of reports using the top menu tab (Fig. 16).

For example, generate a report, "Patients with the syndrome of the second type." To do this, select the appropriate type of report from the top menu. Before us, a dialog box to save the file (Fig. 17). By default, all reports are saved in a special folder reports, 
inside the folder with the software product itself. However, you can choose any way save the file on your hard disk. After selecting the path to the File Name field in specify the file name. All saved files will have the extension txt, which can be viewed by using Notepad.

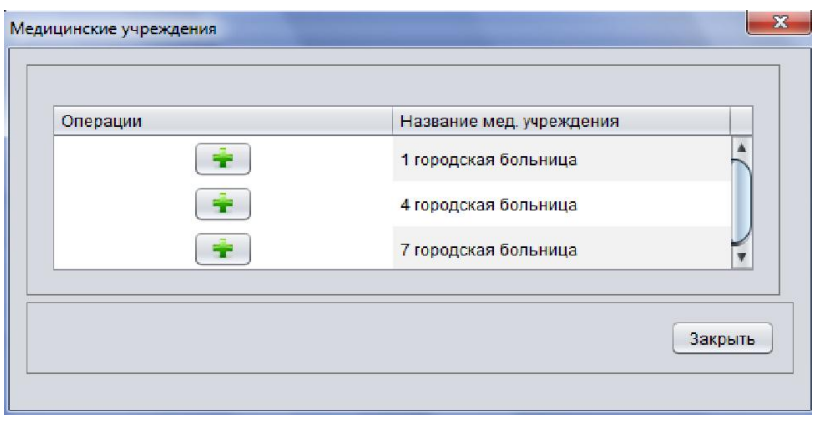

Fig. 15 - Editor of medical institutions.

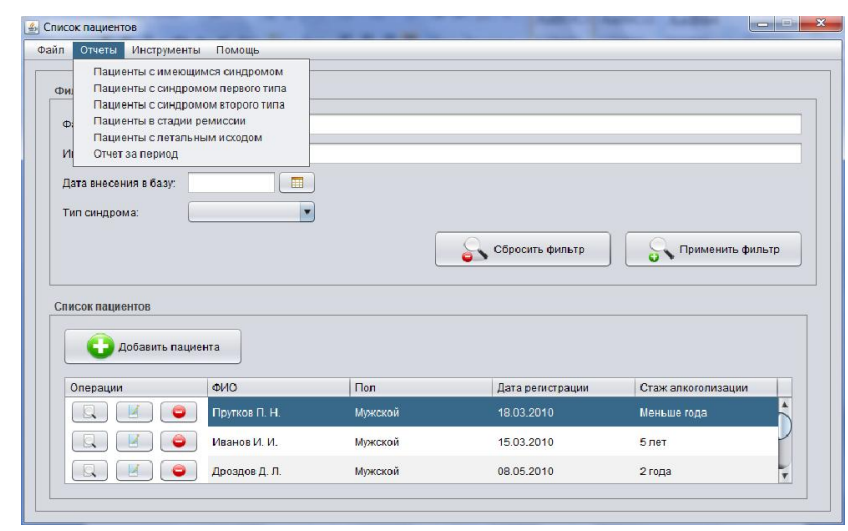

Fig. 16 - Report types.

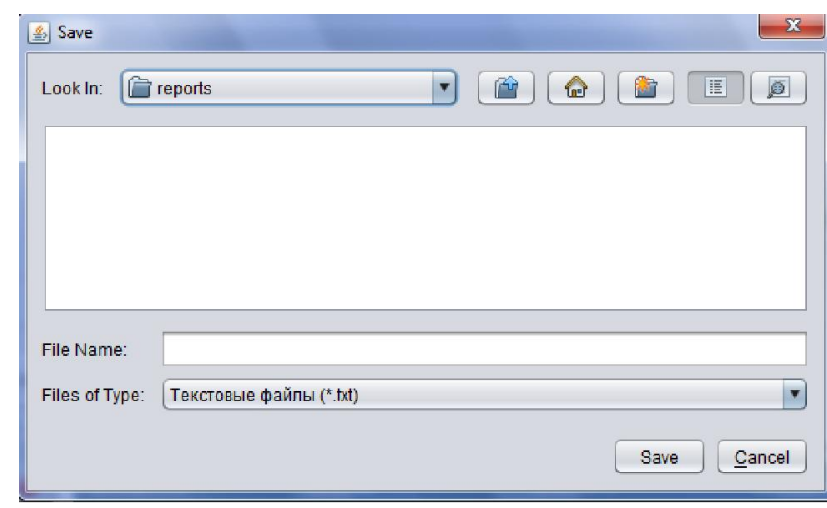

Fig. 17 - The dialog box for saving the report

After pressing the «Save» the message that if we want to see now generated report.

\section{TESTING RESULTS OF THE STUDY}

At the completion of the software product was conducted its testing for the detection and subsequent troubleshooting [5].

Testing included the following items:

1. Testing functional requirements.
Developed product many times progressively elaborated considering insertion adjustments. Therefore, this product fully meets its functional requirements.

2. Testing the user interface.

This application has a friendly interface, the most convenient and intuitive for the user.

3. Testing of individual modules.

Special attention was given to check the correct operation of individual software modules of the product. In particular, the definition of the type of hepatorenal syndrome, report generation, the addition of the patient base, working with editors accounts, medicines and medical facilities.

4. Comprehensive testing.

In addition to individual modules conducted a comprehensive testing of client - server architecture program at a medical facility in Arkhangelsk.

5. Testing rate system boot.

During testing, it was found that the download speed of the system is optimal.

6. Testing boundary conditions.

Testing was performed in the presence of program behavior in determining the boundary condition types syndrome. Upon detection of the syndrome and its type definition is an odd number of significant figures, which do not lead to problems and errors in the data and, ultimately, still based on the results of analyzes will overbalance toward the first or second type.

Testing in the presence of large amounts of information (congestion).

During testing, it was found that for large flows of information the program works without any time delay.

Tests were carried out Arkhangelsk City Clinical Hospital № 1. Data are presented in Table 6.

Table 6. Data Tests Arkhangelsk City Clinical Hospital № 1.

\begin{tabular}{|l|l|c|c|}
\hline № & \multicolumn{1}{|c|}{ Parameter } & $\begin{array}{c}\text { Control } \\
\text { group }\end{array}$ & $\begin{array}{c}\text { Experimental } \\
\text { group }\end{array}$ \\
\hline 1 & Patients number & 46 & 46 \\
\hline 2 & $\begin{array}{l}\text { Patients number with } \\
\text { hepatorenal syndrome } \\
\text { identified }\end{array}$ & 18 & 21 \\
\hline 3 & $\begin{array}{l}\text { The time spent on entering } \\
\text { data into the program (h) }\end{array}$ & 0 & 23 \\
\hline 4 & $\begin{array}{l}\text { Time spent processing the } \\
\text { data in one patient (h) }\end{array}$ & 138 & 18,4 \\
\hline 5 & $\begin{array}{l}\text { Number of doctors } \\
\text { including specialists) }\end{array}$ & $3(3)$ & $2(1)$ \\
\hline 6 & $\begin{array}{l}\text { Level of satisfaction with } \\
\text { their work specialists }\end{array}$ & $63 \%$ & $86 \%$ \\
\hline 6 & $\begin{array}{l}\text { patients number with } \\
\text { detected hepatorenal } \\
\text { syndrome while } \\
\text { revalidating }\end{array}$ & 19 & 21 \\
\hline
\end{tabular}


Testing has shown that the time of diagnosis was reduced in comparison with traditional methods at $69 \%$, with fewer specialists, while job satisfaction of physicians increased by $23 \%$. Diagnostic accuracy hepatorenal syndrome is not dependent on the method of diagnosis.

\section{CONCLUSION}

Creation of the software product is the important stage in hepatorenal syndrome screening. The developed application will allow without special work even in absence of the doctor-expert to define syndrome presence or absence. Besides, the program will cut time for definition and syndrome revealing by a manual method, the costs connected with inspection.

Free software, crossplatform, sufficient simplicity and reliability are the main advantages of the software product. Program approbation is successfully spent in hospitals of Arkhangelsk. The primary tasks put at the very beginning of work are executed.

Tests were carried out Arkhangelsk City Clinical Hospital № 1. Testing has shown that the time of diagnosis was reduced in comparison with traditional methods at $69 \%$, with fewer specialists, while job satisfaction of physicians increased by $23 \%$. Diagnostic accuracy hepatorenal syndrome is not dependent on the method of diagnosis. Testing program showed that the data that gives our program coincide with those of health professionals.

\section{REFERENCES}

[1] S. Sherlock, J. Dooley, Diseases of the Liver and Biliary Tract, A Practical Guide, GEOTAR Medicine, Moscow, 1999, 864 p.

[2] M. Hinz, O. Witzke, G. Gerken, \& A. Canbay, Hepatorenal syndrome, Nephrologe, (8) 4 (2013), pp. 308-316.

[3] V. Gueutin, A. Meftah, G. Desbuissons, L. Debchi, A. Langlois, N. Shehwaro, \& H. Izzedine, Hepatorenal syndrome: Focus, Nephrologie et Therapeutique, (9) 7 (2013), pp. 471-480. (in French)

[4] V. Arroyo, J. Fernandez, \& P. Ginès, Pathogenesis and treatment of hepatorenal syndrome, Seminars in Liver Disease, (28) 1 (2008), pp. 81-95.

[5] J. R. Potts, \& S. Verma, Alcoholic hepatitis: Diagnosis and management in 2012, Expert
Review of Gastroenterology and Hepatology, (6) 6 (2012), pp. 695-710.

[6] A. Lagunov, D. Lagunova, I. Berdennikova, The program of hepatorenal syndrome at the persons abusing alcohol screening carrying out, Proceedings of the $7^{\text {th }}$ IEEE International Conference on Intelligent Data Acquisition and Advanced Computing Systems, (IDAACS'2013), Berlin, 12-14 September 2013, Vol. 1, pp. 275-280.

[7] Site Java, (http://java.sun.com/).

[8] Site Firebird, (http://www.firebirdsql.org/).

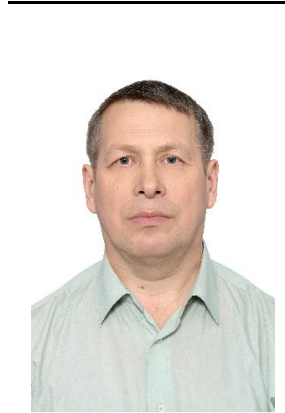

Alexey Lagunov, is the leading expert of department of Computer Science and Electronic Devices of Institute of Natural Sciences and Biomedicine of Northern (Arctic) Federal University named after M.V. Lomonosov, the candidate of sciences, the senior lecturer. Teaches the following subjects of discipline: the electrical engineer and a radio engineering, computer networks, physical computer science. Area of scientific interests: computer wireless networks, distribution of radiowaves. Writes the thesis for a doctor's degree. Supervises over scientific work of students and post-graduate students.

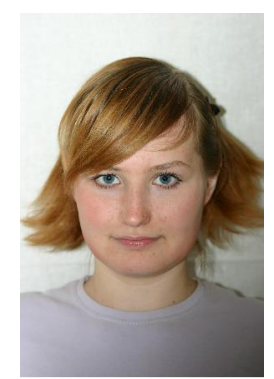

Darina Lagunova, is a student of the of Institute of Natural Sciences and Biomedicine of Northern (Arctic) Federal University named after M.V. Lomonosov. Area of scientific interests: computer wireless networks, distribution of radiowaves, intelligent information systems, medical information systems.

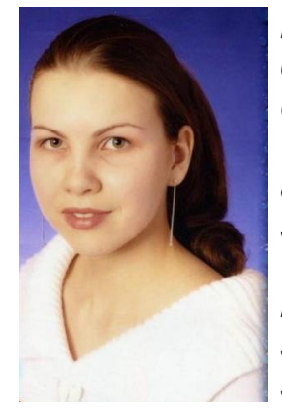

Irina Berdennikova, is a student of the of Institute of Natural Sciences and Biomedicine of Northern (Arctic) Federal University named after M.V. Lomonosov. Area of scientific interests: computer wireless networks, distribution of radiowaves, intelligent information systems, medical information systems. 